\title{
Economically Smart Way to Learning English as a Foreign Language in the Digital World of Today
}

\author{
Dr. Shahida Naz1, Memona Rasheed2, Tahir Rasheed3, Shazia Rasheed4 \\ 1. Assistant Professor, Department of Applied Linguistics, Government College University Faisalabad, \\ Pakistan. \\ 2. Visiting Lecturer, Department of Economics, Government College University Faisalabad, Pakistan \\ 3. Department of English, National University of Modern Languages, (NUML) Multan, Pakistan \\ 4. Secondary School Teacher (SST), Government Girls Higher Secondary School Shujabad, Multan, Pakistan
}

\begin{abstract}
A great number of educational applications (Apps) are available on mobile phones and internet connectivity available on economic price made mobile learning attractive, easy and borderless. This study explores Pakistani EFL students' attitude towards using smartphone apps for learning English as a foreign language (EFL). This study aims at investigating EFL students' attitude and awareness about using smartphone as an economical tool for learning English as a foreign language, moreover, it also aims at examining the effect of their gender as well as their place of living rural/urban area, on their attitude towards using smartphones applications for learning English. The survey research method is used and data were collected through a detailed questionnaire. The researcher distributed 200 questionnaires randomly to graduate level students of English studying at 2 public universities in Pakistan. Findings revealed students' positive attitude towards learning English with smartphone apps without any significant difference of gender or area. Students showed willingness and motivation for using smartphones for language learning purposes in an economic way. The findings suggest that more time, practice and advance teaching pedagogy is required to make it more effective language learning tool in formal and informal situations.
\end{abstract}

Keywords: Innovative Learning, Flipped Learning, Digital Learning, $21^{\text {st }}$ Century Learning, Smart Learning, Economic way of Learning 